\title{
Association Between Dispensing of Low-value Oral Albuterol and Removal From Medicaid Preferred Drug Lists
}

Anna Volerman ( $\sim$ avolerman@uchicago.edu )

University of Chicago

Alison Pelczar

Harris School of Public Policy

Rena Conti

Boston University Questrom School of Business

Christina Ciaccio

University of Chicago

Kao-Ping Chua

University of Michigan Medical School

\section{Research Article}

Keywords: Albuterol, low-value care, preferred drug list, Medicaid

Posted Date: February 8th, 2022

DOI: https://doi.org/10.21203/rs.3.rs-1300629/v1

License: (9) This work is licensed under a Creative Commons Attribution 4.0 International License.

Read Full License 


\section{Abstract}

Background: Oral albuterol has worse efficacy and side effects compared with inhaled albuterol, and thus its use has been discouraged for decades. Drug inclusion or exclusion on formularies have been associated with reductions in low-value care. This study examines dispensing of oral albuterol and inclusion of oral albuterol on state Medicaid drug formularies--Preferred Drug Lists (PDLs). It also evaluates the association between removal of oral albuterol from the PDL and dispensing levels.

Methods: This quasi-experimental study determined oral albuterol inclusion on PDLs and dispensing between 2011-2018, using Medicaid program websites and the State Drug Utilization Database. Using a difference-in-differences model, we examine the association between removal of oral albuterol from Arkansas' Medicaid PDL in 2014 and dispensing of this drug through Medicaid, with lowa as a control state. The outcome measure was the percent of all albuterol prescriptions that were for oral albuterol.

Results: A total of 28 state Medicaid PDLs included at least one formulation of oral albuterol in 2018. In $2018,179,446$ oral albuterol prescriptions were dispensed to Medicaid beneficiaries nationally with Medicaid programs paying a total of $\$ 3.7$ million for these prescriptions. Removal of oral albuterol syrup from the Arkansas PDL in March 2014 was associated with a more rapid decline in dispensing compared with lowa.

Conclusions: Findings suggest that removal of low-value medications, such as oral albuterol, from PDLs may be one avenue by which state Medicaid programs can reduce wasteful daspending while improving guideline-based care.

\section{Background}

Low-value services are those that fail to improve health or result in small health improvements relative to their cost. $(1,2)$ Use of low-value services is estimated to cost at least $\$ 75-100$ billion annually $(3)$ and is widespread among all populations, including children, $(4,5)$ non-elderly adults, $(6)$ and Medicare beneficiaries.(7) Prior research suggests health insurer coverage and reimbursement policies, including drug inclusion or exclusion on formularies,(8) can reduce low-value care and promote high-value care. $(9,10)$ However, the drugs examined in these past studies had both high-value and low-value uses.

State Medicaid programs can reduce dispensing of low-value prescription drugs to covered beneficiaries by removing them from Preferred Drug Lists (PDLs), lists of medications covered by Medicaid without prior authorization. One example of a low-value drug is oral albuterol, an asthma quick-relief medication which is available in both tablet and syrup formulations. Compared with inhaled albuterol, oral albuterol has worse efficacy and side effects.(11)

Clinical guidelines have explicitly dissuaded healthcare professionals from prescribing oral rescue medications for decades. The original asthma guidelines in the United States, published in 1991, recommend aerosol therapy over oral delivery due to the faster onset of relief, fewer adverse effects, and 
ability to achieve the same relief with a lower dose.(12) ${ }^{34}$ The two guideline updates (1997 and 2007) make no mention of oral beta ${ }_{2}$-agonist medications as treatment options. $(13,14)$ Similarly, international guidelines either explicitly do not recommend oral albuterol or make no mention of it.(15,16)

Despite its absence in guidelines and calls to cease its prescription,(17) oral albuterol continues to be used. A study conducted with a low-income population in Harlem, New York City showed that $62 \%$ of preschool-age children with asthma used oral albuterol in the prior four weeks; a slightly greater proportion used inhaled beta ${ }_{2}$-agonist medications ( $72 \%$ in prior four weeks), and very few used inhaled corticosteroids or other controller medications.(18)

Given its continued use, oral albuterol is a good model for evaluating the potential of PDLs to reduce lowvalue drug dispensing because it is considered universally low-value across all populations and uses. This study examines dispensing of oral albuterol, conducts an inventory of oral albuterol inclusion on Medicaid PDLs, and evaluates the association between the removal of oral albuterol from the Medicaid PDL and dispensing of this drug.

\section{Methods}

This quasi-experimental study examines oral albuterol dispensing and Medicaid PDLs between 20112018.

Data source for albuterol dispensing. We obtained data on albuterol prescription dispensing to Medicaid enrollees in all states between 2011-2018 from the State Drug Utilization Database, which is maintained by the Centers for Medicare \& Medicaid Services.(19) This database reports the quarterly number of prescriptions dispensed to Medicaid enrollees by national drug code (NDC). We identified products containing albuterol using a list of NDCs obtained from IBM Micromedex RED BOOK (see Table E1 in Online Supplement for full list).(20)

In the State Drug Utilization Database, data are suppressed for any quarterly count less than 11 . We imputed suppressed counts in the same manner as prior studies using the same dataset. ${ }^{15}$ This method leveraged the discrepancy between the sum of state-level totals and the national total. Imputed counts were weighted inverse to the number of quarters during the year that the count was suppressed, so that counts less frequently suppressed received greater weight (see Methods E1 in Online Supplement for description of the full imputation methodology). When suppressed cells were dropped instead of imputed, results from difference-in-differences analyses were unchanged (see Table E2 in Online Supplement, which contains the results without imputed counts).

Data source for PDLs. For the analysis of oral albuterol inclusion on 2018 PDLs, data on PDLs were obtained from Medicaid program websites. If PDLs were unavailable on websites, published minutes and notes for the state's Pharmacy and Therapeutics Committee were reviewed for indications of changes. If neither was available, the state's Medicaid office was contacted to clarify coverage or obtain prior PDL versions. When more than one list was published during 2018, all versions were reviewed to evaluate 
whether changes in coverage occurred. An albuterol formulation was considered preferred if it was included on the PDL and was available without prior authorization; otherwise, it was considered nonpreferred.

The analysis was limited to PDLs for FFS plans. Four states (Hawaii, New Jersey, New Mexico, and South Dakota) did not use PDLs for their FFS plans in 2018(21) and were excluded, leaving 46 states and the District of Columbia (henceforth referred to as "states"). Of the 47 states, 11 had FFS only (no managed care organization (MCO) plans) in 2018, 13 had both FFS and MCO plans and used the same PDL for both, and 23 had both FFS and MCO plans but used different PDLs.(21) For these 23 states, the PDLs for MCO plans were not examined.

For each of the 47 states using PDLs in 2018, we determined whether at least one formulation of oral albuterol was considered preferred on the state's 2018 FFS PDL. Additionally, we calculated total reimbursement for oral albuterol prescriptions across all state Medicaid programs in 2018. We conducted these analyses to determine the degree to which Medicaid programs continue to include low-value oral albuterol on PDLs and to estimate the direct amount of wasteful spending on this drug by Medicaid programs.

Selection of states for difference-in-differences analysis. Nineteen states did not consider any form of oral albuterol as preferred on their FFS PDL in 2018. For these states, PDLs from 2011-2018 were reviewed to determine whether any oral albuterol formulations had changed from preferred to nonpreferred status. Changes were identified in six states. Five states were not considered, because PDL removal occurred too early or late during the study period to have sufficient pre-intervention or postintervention data or because dispensing totals of oral albuterol before PDL removal were too low to measure impact. In contrast, dispensing totals before PDL removal were high enough to measure impact in Arkansas, which changed oral albuterol syrup from preferred to non-preferred in March 2014, midway through the study period.

To identify potential control states for Arkansas, the percentage of dispensed albuterol prescriptions that were for oral albuterol syrup in 2011 was calculated for each state. This percentage was used because it is unaffected by the number of Medicaid enrollees, in contrast to raw prescription counts. States with a similar percentage of dispensed albuterol prescriptions that were for oral albuterol syrup to Arkansas in 2011 were considered. lowa was chosen as the control state because the trends for this percentage during the pre-intervention period between 2011 and 2013 were parallel to Arkansas.

Statistical analysis. To examine the association between removal of oral albuterol syrup from Arkansas' PDL in 2014 and dispensing of this drug, a difference-in-differences analysis was performed using data from 2011-2018. The pre-intervention period consisted of 12 quarters between January 2011 and December 2013, and the post-intervention period included 19 quarters between April 2014 and December 2018. The quarter containing March 2014 was excluded. A second difference-in-differences model including only data through 2015 was also estimated, as lowa started to use MCOs in 2016, while Arkansas had only FFS plans from 2011-2018. 
The dependent variable was the percentage of albuterol prescriptions dispensed that were for oral albuterol syrup. The model included indicators for quarter to adjust for seasonal patterns in dispensing. Robust standard errors were used.

To test the parallel trends assumption, a linear regression model was fit using only data from 2011-2013. Terms included time as a continuous variable, an indicator for Arkansas, and their interaction.

\section{Results}

Oral albuterol dispensing and inclusion on PDLs in 2018.

In $2018,179,446$ oral albuterol prescriptions were dispensed to Medicaid beneficiaries nationally. This total included 10,736 prescriptions for immediate-release tablets, 3,182 for extended-release tablets, and 165,528 for syrup. In total, Medicaid programs paid \$3.7 million for these prescriptions.

In 2018, 28 of the 47 states that used PDLs included at least one oral albuterol formulation on their PDL. Of these 28 states, 26 had preferred status for oral albuterol syrup and 15 had preferred status for at least one formulation of oral albuterol tablet (immediate-release or extended-release) (Table 1).

Removal of albuterol syrup from Arkansas PDL.

In Arkansas, oral albuterol syrup comprised an average $0.93 \%$ of all albuterol prescriptions dispensed per quarter under Medicaid during 2011-2013, compared to 0.83\% in lowa. This percentage declined over time in both states. Rates of decline were similar $(p=0.50)$, suggesting the parallel trends assumption was met.

After Arkansas removed albuterol syrup from the PDL in March 2014, the percent of dispensed albuterol prescriptions that were for albuterol syrup almost immediately declined to levels near zero, while this percentage declined more slowly in lowa (Figure 1). PDL removal was associated with a 0.33 percentagepoint greater decline in this percentage in Arkansas compared with lowa $(p=0.01)$ (Table 2). Restricting the time period to $2011-2015$ produced similar results (differential decrease of 0.43 percentage points, $\mathrm{p}=0.02)$.

\section{Discussion}

We report that more than half of state PDLs still included oral albuterol in 2018 despite its worse efficacy and side effect profile compared with inhaled albuterol. Moreover, we provide natural quasi-experimental evidence that removal of oral albuterol from the PDLs of Arkansas was associated with rapid declines in dispensing of these drugs. Findings suggest state Medicaid programs can reduce wasteful spending and potentially patient health by excluding low-value drugs from PDLs.

Oral albuterol has not been recommended as part of clinical guidelines for asthma for over three decades. Despite evidence-based recommendations in place, this study demonstrates that it continues to 
be utilized with over 175,000 prescriptions filled in 2018. Further, in the same year, more than half of Medicaid programs still included oral albuterol on PDLs. While total spending on oral albuterol is modest at $\$ 3.7$ million, this amount only represents the direct costs of oral albuterol dispensing. The true cost is likely higher, as the use of oral albuterol over more effective inhaled formulations may lead to avoidable and costly emergency department visits for asthma exacerbations or potentially symptoms related to the side effects of oral albuterol.(22) Consequently, findings suggest the potential for substantial savings if Medicaid programs removed oral albuterol from PDLs.

Formulary placement, including PDL inclusion, can be a tool to promote use of high-value care, as seen with curative hepatitis $C$ treatment.(23) Conversely, PDL removal can be used to contain costs. Although studies have documented decreases in dispensing following removal of several expensive drugs from PDLs, $(9,10)$ our study provides some of the first evidence that PDL removal can reduce dispensing of a drug that is universally low-value.

While this study focused on oral albuterol, findings may be applicable to other low-value drugs. For example, a substantial amount of wasteful spending occurs for combination products for which individual products are substantially less expensive,(24) such as ibuprofen/famotidine (Duexis). Future studies should examine whether removal of these and other low-value drugs from PDLs can reduce wasteful spending.

This study has several limitations. First, in the Medicaid dispensing database, there may be some lag between when a prescription is dispensed and when it was reported. In addition, data sources did not report why Arkansas removed oral albuterol from its PDL. Consequently, it is unclear whether the resulting reductions in dispensing were intended or not. Finally, the suppression of small cells in this database meant that imputation was necessary; we show that this did not significantly impact results.

\section{Conclusion}

Medicaid PDL removal may be a powerful tool for reducing dispensing of low-value drugs to Medicaid recipients. State Medicaid programs and insurers more broadly should consider removing all low-value drugs from formularies and PDLs in order to reduce wasteful spending and potentially improve patient health by decreasing use of medications that have more effective alternatives.

\section{Abbreviations}

FFS $=$ Fee for service

$\mathrm{MCO}=$ Managed Care Organization

NDC $=$ National Drug Code

PDL $=$ Preferred drug list 


\section{Declarations}

\section{Ethics approval and consent to participate}

Not applicable. This study utilized state-level data that was publicly available and included not individual information; thus, ethics or human subjects research approval was not required.

\section{Consent for publication}

Not applicable.

\section{Availability of data and materials}

All data generated or analysed during this study are included in this published article and its supplementary information files.

\section{Competing interests}

The authors declare they have no competing interests.

\section{Funding}

Anna Volerman is supported by a career development award from the National Heart, Lung, and Blood Institute (grant number K23HL143128); she also receives funding from Robert Wood Johnson Foundation. Kao-Ping Chua is supported by a career development award from the National Institute on Drug Abuse (grant number K08DA048110). Christina Ciaccio is supported by a generous donation from Paul and Mary Yovovich.

\section{Authors' contributions}

$\mathrm{AV}, \mathrm{AP}, \mathrm{KC}$ conceptualized and designed the study.

AP organized the data and performed analyses.

AP and AV drafted the manuscript.

$\mathrm{CC}, \mathrm{KC}, \mathrm{RC}$ critically reviewed and revised the manuscript.

All authors interpreted the data and also read and approved the final manuscript.

\section{Acknowledgements}

We acknowledge Mary Akel, MPH for her assistance with manuscript editing.

\section{References}


1. Baker DW, Qaseem A, Reynolds PP, Gardner LA, Schneider EC. Design and Use of Performance Measures to Decrease Low-Value Services and Achieve Cost-Conscious Care. Ann Intern Med. 2013 Jan 1;158(1):55-9.

2. Gruber J, Maclean JC, Wright B, Wilkinson E, Volpp K. The Impact of Increased Cost-Sharing on Utilization of Low Value Services: Evidence from the State of Oregon [Internet]. Rochester, NY: Social Science Research Network; 2017 Jan [cited 2021 Dec 20]. Report No.: ID 2903099. Available from: https://papers.ssrn.com/abstract=2903099

3. Shrank WH, Rogstad TL, Parekh N. Waste in the US Health Care System: Estimated Costs and Potential for Savings. JAMA. 2019 Oct 15;322(15):1501-9.

4. Chua K-P, Schwartz AL, Volerman A, Conti RM, Huang ES. Use of Low-Value Pediatric Services Among the Commercially Insured. PEDIATRICS. 2016 Dec 1;138(6):e20161809-e20161809.

5. Chua K-P, Schwartz AL, Volerman A, Conti RM, Huang ES. Differences in the Receipt of Low-Value Services Between Publicly and Privately Insured Children. Pediatrics. 2020 Feb;145(2):e20192325.

6. Reid RO, Rabideau B, Sood N. Low-Value Health Care Services in a Commercially Insured Population. JAMA Intern Med. 2016 Oct 1;176(10):1567-71.

7. Schwartz AL, Landon BE, Elshaug AG, Chernew ME, McWilliams JM. Measuring low-value care in Medicare. JAMA Intern Med. 2014 Jul;174(7):1067-76.

8. Morgan S, Hanley G, Greyson D. Comparison of tiered formularies and reference pricing policies: a systematic review. Open Med. 2009 Aug 4;3(3):e131-9.

9. Dillender M. What happens when the insurer can say no? Assessing prior authorization as a tool to prevent high-risk prescriptions and to lower costs. J Public Econ. 2018 Sep 1;165:170-200.

10. Faul M, Bohm M, Alexander C. Methadone Prescribing and Overdose and the Association with Medicaid Preferred Drug List Policies - United States, 2007-2014. MMWR Morb Mortal Wkly Rep. 2017 Mar 31;66(12):320-3.

11. Price D, Bosnic-Anticevich S, Briggs A, Chrystyn H, Rand C, Scheuch G, et al. Inhaler competence in asthma: Common errors, barriers to use and recommended solutions. Respir Med. 2013 Jan 1;107(1):37-46.

12. Expert Panel Report 1: Guidelines for the Diagnosis and Management of Asthma. Bethesda, MD: U.S. Department of Health and Human Services; National Institutes of Health; National Heart, Lung, and Blood Institute; National Asthma Education and Prevention Program; 1991.

13. Expert Panel Report 2: Guidelines for the Diagnosis and Management of Asthma. Bethesda, MD: U.S. Department of Health and Human Services; National Institutes of Health; National Heart, Lung, and Blood Institute; National Asthma Education and Prevention Program; 1997. Report No.: NIH Publication No. 97-4051.

14. Expert Panel Report 3: Guidelines for the Diagnosis and Management of Asthma. Bethesda, MD: U.S. Department of Health and Human Services; National Institutes of Health; National Heart, Lung, and Blood Institute; National Asthma Education and Prevention Program; 2007. Report No.: NIH Publication No. 07-4051. 
15. Global Initiative for Asthma. GINA Report: Global Strategy for Asthma Management and Prevention. 2021 [cited 2021 Dec 10]. Available from: https://ginasthma.org/gina-reports/

16. British guideline on the management of asthma. Healthcare Improvement Scotland; 2019 Jul. Report No.: SIGN 158.

17. Craig S, Tuszynski M, Armstrong D. It is time to stop prescribing oral salbutamol. Aust Fam Physician. 2016 Apr;45(4):245-7.

18. Bonner S, Matte T, Rubin M, Fagan JK, Ahern J, Evans D. Oral beta2-agonist use by preschool children with asthma in East and Central Harlem, New York. J Asthma. 2006 Feb;43(1):31-5.

19. State Drug Utilization Data [database online]. Baltimore, MD; 2021 [cited 2021 Jan 4]. Available from: https://www.medicaid.gov/medicaid/prescription-drugs/state-drug-utilization-data/index.html

20. IBM Micromedex RED BOOK [database online]. Greenwood Village, CO: Truven Health Analytics; 2020 [cited 2020 Jan 22]. Available from: https://www.ibm.com/products/micromedex-red-book

21. State Medicaid Preferred Drug Lists [Internet]. Kaiser Family Foundation; 2020 Jul [cited 2021 Apr 9]. Available from: https://www.kff.org/other/state-indicator/medicaid-preferred-drug-lists/

22. Murawski MM, Abdelgawad T. Exploration of the impact of preferred drug lists on hospital and physician visits and the costs to Medicaid. Am J Manag Care. 2005 Jan;11 Spec No:SP35-42.

23. Washington State Department of Health. Plan to Eliminate Hepatitis C in Washington State by 2030 [Internet]. Olympia, WA; 2019 Jul [cited 2021 Dec 20]. Available from: https://www.doh.wa.gov/Portals/1/Documents/Pubs/150nonDOH-HepCFreeWA-PlanJuly2019.pdf

24. Vela L. Reducing Wasteful Spending in Employers' Pharmacy Benefit Plans [Internet]. 2019 Aug [cited 2021 Dec 20]. Available from: https://www.commonwealthfund.org/publications/issuebriefs/2019/aug/reducing-wasteful-spending-employers-pharmacy-benefit-plans

\section{Tables}

Table 1. Oral albuterol inclusion status on Medicaid fee-for-service preferred drug lists (PDLs) in $2018^{1}$ 


\begin{tabular}{|c|c|c|}
\hline \multirow[t]{2}{*}{ State } & \multicolumn{2}{|c|}{ Status of albuterol on PDL } \\
\hline & Tablet preferred $^{2}$ & Syrup preferred \\
\hline Alabama & $\mathrm{x}$ & $x$ \\
\hline Alaska & $\mathrm{x}$ & $\mathrm{x}$ \\
\hline Arizona & & $\mathrm{x}$ \\
\hline \multicolumn{3}{|l|}{ Arkansas } \\
\hline California & $x$ & $x$ \\
\hline \multicolumn{3}{|l|}{ Colorado } \\
\hline Connecticut & & $x$ \\
\hline Delaware & & $\mathrm{x}$ \\
\hline District of Columbia & & $x$ \\
\hline Florida & & $x$ \\
\hline \multicolumn{3}{|l|}{ Georgia } \\
\hline \multicolumn{3}{|l|}{ Idaho } \\
\hline Illinois & & $\mathrm{x}$ \\
\hline Indiana & & $\mathrm{x}$ \\
\hline lowa & $\mathrm{x}$ & $\mathrm{x}$ \\
\hline \multicolumn{3}{|l|}{ Kansas } \\
\hline \multicolumn{3}{|l|}{ Kentucky } \\
\hline Louisiana & & $\mathrm{x}$ \\
\hline \multicolumn{3}{|l|}{ Maine } \\
\hline Maryland & & $\mathrm{x}$ \\
\hline Massachusetts & $\mathrm{x}$ & $x$ \\
\hline Michigan & & $x$ \\
\hline Minnesota & & $\mathrm{x}$ \\
\hline Mississippi & $\mathrm{x}$ & \\
\hline \multicolumn{3}{|l|}{ Missouri } \\
\hline \multicolumn{3}{|l|}{ Montana } \\
\hline Nebraska & & $x$ \\
\hline
\end{tabular}


Nevada

New Hampshire

New York

North Carolina ${ }^{3}$

$\mathrm{X}$

X

North Dakota

X

X

Ohio

Oklahoma

Oregon

Pennsylvania

Rhode Island

South Carolina

$x$

$\mathrm{x}$

Tennessee

$x$

X

Texas

X

Utah

X

X

Vermont

X

X

Virginia

Washington

$x$

$\mathrm{x}$

West Virginia

X

Wisconsin

X

X

Wyoming

National 15 26

${ }^{1}$ Four states did not use a fee-for-service preferred drug list and thus are not listed: Hawaii, New Jersey, New Mexico, and South Dakota.

${ }^{2}$ For albuterol tablets, states may have considered immediate-release and/or extended-release tablets to be preferred. These formulations were categorized separately, as some states considered one to be preferred and the other to be non-preferred. Table shows states that had at least one formulation of tablets as preferred.

${ }^{3}$ Oral albuterol tablets were removed from the PDL in North Carolina in December 2018. 
Table 2. Results from difference-in-differences analysis examining association between dispensing and removal of oral albuterol syrup from Arkansas' PDL in March 2014

\begin{tabular}{|c|c|c|c|c|}
\hline & \multicolumn{2}{|l|}{ 2011-2018 } & \multicolumn{2}{|c|}{$\begin{array}{l}\text { 2011-2015 } \\
\text { (Sensitivity Analysis) }\end{array}$} \\
\hline & $\begin{array}{l}\text { Estimate } \\
\text { (SE) }\end{array}$ & $p$ & $\begin{array}{l}\text { Estimate } \\
\text { (SE) }\end{array}$ & $p$ \\
\hline Intercept & $1.04(0.12)$ & $<0.001$ & $\begin{array}{l}1.19 \\
(0.14)\end{array}$ & $<0.001$ \\
\hline Difference in the pre-intervention period & $0.09(0.12)$ & 0.43 & $\begin{array}{l}0.09 \\
(0.10)\end{array}$ & 0.37 \\
\hline Change during post-intervention period & $-0.58(0.08)$ & $<0.001$ & $\begin{array}{l}-0.44 \\
(0.09)\end{array}$ & $<0.001$ \\
\hline $\begin{array}{l}\text { Additional change during post-intervention period in } \\
\text { Arkansas }\end{array}$ & $-0.33(0.13)$ & 0.01 & $\begin{array}{l}-0.43 \\
(0.15)\end{array}$ & 0.01 \\
\hline \multicolumn{5}{|l|}{ SE - standard error } \\
\hline \multicolumn{5}{|c|}{ Dependent variable is percentage of albuterol prescriptions that were for oral albuterol syrup. } \\
\hline
\end{tabular}

\section{Figures}




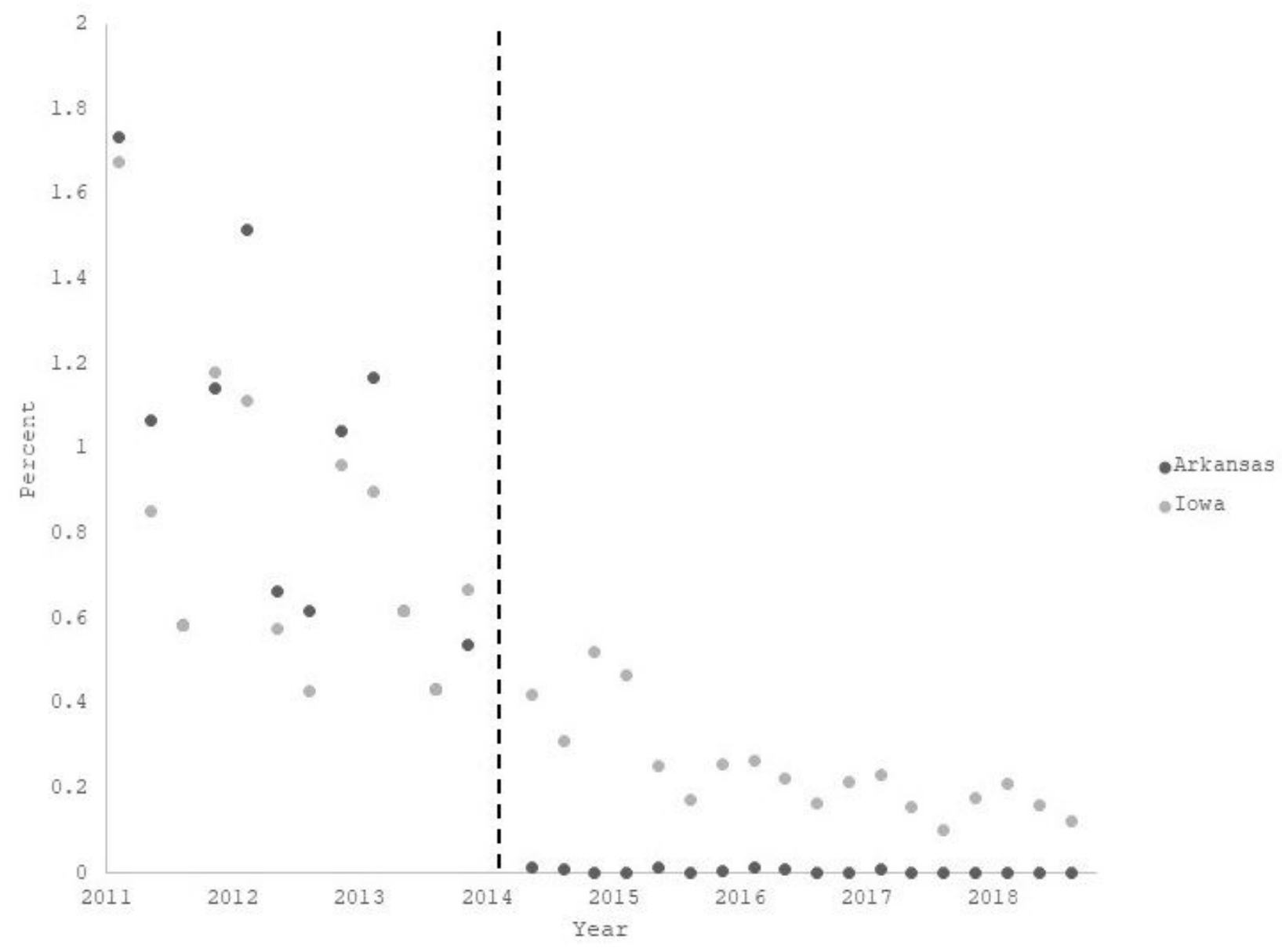

Figure 1

Percent of dispensed albuterol prescriptions that were for oral albuterol syrup prescriptions in lowa and Arkansas, by quarter. This percentage dropped sharply in Arkansas in quarter 2 of 2014, following the removal of oral albuterol from the Arkansas Medicaid preferred drug list in March 2014. A sharp drop is not observed in lowa.

\section{Supplementary Files}

This is a list of supplementary files associated with this preprint. Click to download.

- Onlinesupplementfull.docx

- Supplementdata.xlsx 